Column 3 in the table gives the $\sin ^{2} \theta$ values corresponding to various bands and lines. Column 4 gives the plane indexes based on a cubic or pseudo-cubic structure taking the lattice spacing as $8 \cdot 18 \mathrm{~A}$. The assignment of these indices is perhaps more apparent than real. It does not mean necessarily that our results are in favour of the crystallite theory of glasses, as no crystalline modification of $\mathrm{SiO}_{2}$ can fall into this scheme. Moreover, the occurrence of the bands and their relative intensities vary with the specimen and with different circumstances. We are not of the opinion that the sharp lines are due to devitrification if the word 'devitrification' has its usual significance, since it is extremely unlikely that

\section{Band Spectrum of Sodium Hydride}

The band spectrum of sodium hydride has been studied by Hori ${ }^{1,2}$ and Iater by Olsson ${ }^{3}$. Olsson concluded from his analysis of the spectrum of $\mathrm{NaD}$ that the values of $v^{\prime}$ given by Hori ${ }^{2}$ for $\mathrm{NaH}$ should be raised by three units. The results given below were obtained with the view of supplying the missing data for the three lowest vibrational levels of the excited state, which are of especial interest for comparison with the corresponding data for the hydrides of the other alkali metals.

The spectrum was obtained from a discharge tube of the type described by Pearse and Gaydon", and

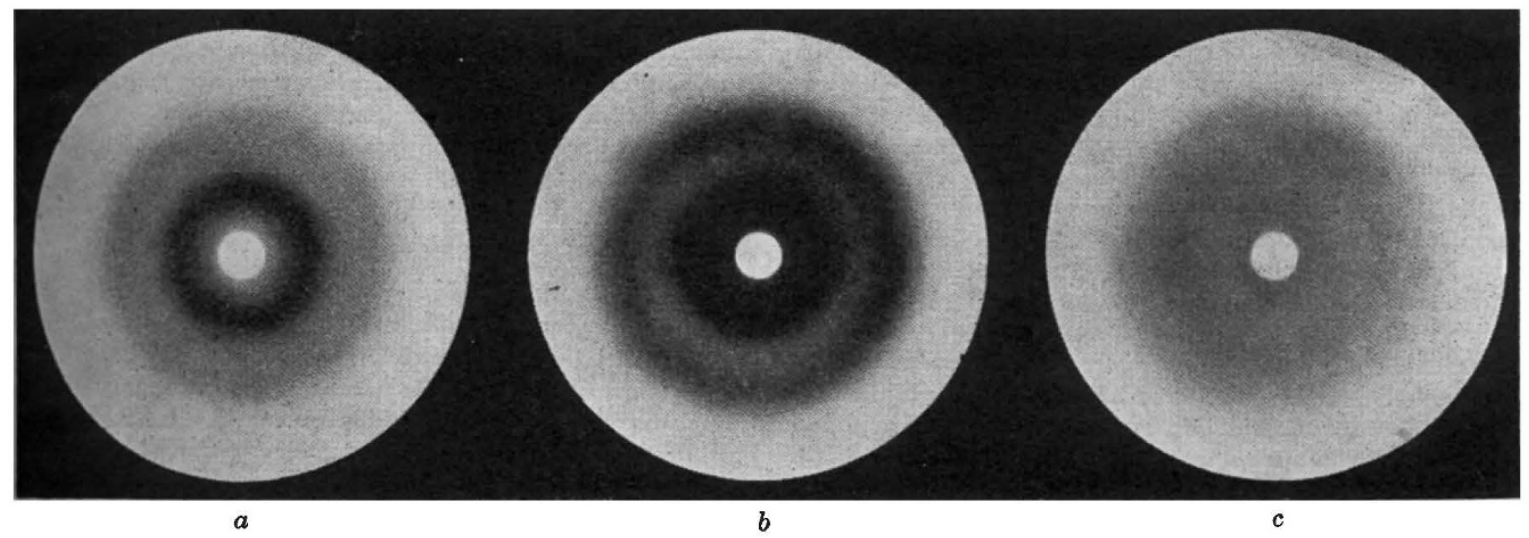

when glass is devitrified the diffraction from the crystallites should have but a few sharp lines while the others remain diffuse.

The difference shown by the Debye-Scherrer photographs and the pin-hole transmission photographs may be interpreted on the ground that on powdering a glass a certain freedom of re-arrangement is regained ${ }^{5}$, thus causing certain changes in the structure. This point has been verified by taking a pin-hole transmission photograph of a slab of powder. The photograph comes out to be the same as that taken with the Debye-Scherrer camera, as shown in photograph $c$.

We have noticed that in the transmission photographs the relative intensities of the two bands $O$ and $B$ may change even with different locations of the same specimen. This appears to support Prins's idea that the degree of organization of glasses may be appreciably different in neighbouring small regions ${ }^{6}$. In other words, large fluctuations do occur in vitreous silica.

Fourier integral analysis is now being used to investigate from our own photographs the possible radial distribution of the scattering centres.

\section{S. S. Lv.}

Y. L. Chang.

Institute of Radium, Shanghai.

\footnotetext{
${ }^{1}$ Parmelee, Clark and Badger, J. Soc. Glass Tech., 13, 285 (1929).

'Randall, Rooksby and Cooper, Nature, 125, 458 (1930).

'Warren, Krutter and Morningstar, J. Amer. Ceramic Soc., 19, 202 (1936); Warren, $J$. Applied Phys., 8, 645 (1937).

- Hartleif, G., Z. anorg. u. allg. Chem., 238, 353 (1938).

- See Bernal's discussion on glass. Trans. Faraday Soc., 33, 113 (1937). Prins, J. A., Trans. Faraday Soc., 33, 110 (1937).
}

grating photographs were taken (dispersions $2 \cdot 6$ and $1.9 \mathrm{~A} . / \mathrm{mm}$.) in the region $\lambda \lambda 640,0-4900$. The results of the analysis of the spectrum are summarized below.

Origins of new bands :

\begin{tabular}{|c|c|c|c|c|c|}
\hline$\left(v^{\prime}, v^{\prime \prime}\right)$ & $\boldsymbol{\nu}$ & $\lambda$ & $\left(v^{\prime}, v^{\prime \prime}\right)$ & $\nu$ & $\lambda$ \\
\hline $\begin{array}{l}(2,3) \\
(3,3)\end{array}$ & $\begin{array}{l}19659 \cdot 8 \\
19996 \cdot 9\end{array}$ & $\begin{array}{l}5085 \cdot 1 \\
4999 \cdot 4\end{array}$ & $\begin{array}{l}(1,6) \\
(2,6) \\
(4,6)\end{array}$ & $\begin{array}{l}16375 \cdot 6 \\
16705 \cdot 6 \\
17386 \cdot 6\end{array}$ & $\begin{array}{l}6105 \cdot 0 \\
5984 \cdot 4 \\
5750 \cdot 0\end{array}$ \\
\hline $\begin{array}{l}(2,4) \\
(3,4) \\
(4,4) \\
(5,4) \\
(6,4) \\
(7,4)\end{array}$ & $\begin{array}{l}18638 \cdot 6 \\
18975 \cdot 8 \\
19319 \cdot 5 \\
19669 \cdot 5 \\
20023 \cdot 2 \\
20380 \cdot 4\end{array}$ & $\begin{array}{l}5363 \cdot 7 \\
5268 \cdot 4 \\
5174 \cdot 7 \\
5082 \cdot 6 \\
4992 \cdot 8 \\
4905 \cdot 3\end{array}$ & $\begin{array}{l}(3,7) \\
(4,7) \\
(5,7)\end{array}$ & $\begin{array}{l}16130 \cdot 0 \\
16473 \cdot 7 \\
16823 \cdot 4 \\
17534 \cdot 6\end{array}$ & $\begin{array}{l}6197 \cdot 9 \\
6068 \cdot 6 \\
5942 \cdot 5 \\
5701 \cdot 4\end{array}$ \\
\hline $\begin{array}{l}(1,5) \\
(2,5) \\
(3,5) \\
(5,5) \\
(6,5)\end{array}$ & $\begin{array}{l}17324 \cdot 3 \\
17654 \cdot 3 \\
17991 \cdot 5 \\
18685 \cdot 0 \\
19038 \cdot 8\end{array}$ & $\begin{array}{l}5770 \cdot 6 \\
5662 \cdot 8 \\
5556 \cdot 6 \\
5350 \cdot 4 \\
5251 \cdot 0\end{array}$ & $\begin{array}{l}(5,8) \\
(6,8) \\
(7,8)\end{array}$ & $\begin{array}{l}159464 \\
163005 \\
16657 \cdot 7\end{array}$ & $\begin{array}{l}6269 \cdot 3 \\
6133 \cdot 1 \\
6001 \cdot 6\end{array}$ \\
\hline
\end{tabular}

$v=22719 \cdot 1+\left(310 \cdot 6 u^{\prime}+5 \cdot 41 u^{\prime 2}-0.197 u^{\prime 3}-0.00073 u^{\prime 4}+\right.$ $\left.0.000073 u^{\prime 5}\right)-\left(1172 \cdot 2 u^{\prime \prime}-19 \cdot 72 u^{\prime 2}+0 \cdot 160 u^{\prime \prime 3}-0.005 u^{\prime \prime 4}\right)$,

where $u=v+\frac{1}{2}$.

Rotational constants for the lower levels of the excited state :

\begin{tabular}{cllll}
$y^{\prime}$ & $\vdots$ & \multicolumn{1}{c}{1} & \multicolumn{1}{c}{2} & \multicolumn{1}{c}{3} \\
$B^{\prime}$ & $\vdots$ & $\mathbf{1} \cdot 823$ & $\mathbf{1} \cdot 875$ & $\mathbf{1} \cdot 908$ \\
$-D^{\prime} \times 10^{4}$ & $\vdots$ & $2 \cdot 25$ & $2 \cdot 25$ & $2 \cdot 20$ \\
$F^{\prime} \times 10^{8}$ & $:$ & $5 \cdot 1$ & $3 \cdot 9$ & $\mathbf{3} \cdot 0$
\end{tabular}

Rotational constants for the ground-leve :

$$
\begin{aligned}
B^{\prime \prime} & =4 \cdot 886-0 \cdot 129 u^{\prime \prime} \\
-D^{\prime \prime} \times 10^{4} & =2 \cdot 76+0 \cdot 20 u^{\prime \prime}-0.021 u^{\prime \prime} \\
F^{\prime \prime} \times 10^{8} & =1 \cdot 7
\end{aligned}
$$

It is hoped to publish the analysis soon in greater detail ; further work is also in hand.

$$
\begin{aligned}
& \text { Imperial College, } \\
& \text { London, S.W.7. }
\end{aligned}
$$

R. C. Pankhurst.

' Hori, T., Z. Phys., 62, 352 (1930)

${ }^{2}$ Hori, T., Z. Phys., 71, 478 (1931).

$s$ Olsson, E., Z. Phys., 93, 206 (1935).

- Pearse, R. W. B., and Gaydon, A. G., Proc. Phys. Soc., 50, 201 (1938). 